Wafaa Gh Al-Shahery BDS, MSc (Asst. Lec.)

\section{Bolton Tooth Size Discrepancy among Mosul Families}

\section{Dept of Pedod, Orthod and Prev Dentistry}

College of Dentistry, University of Mosul

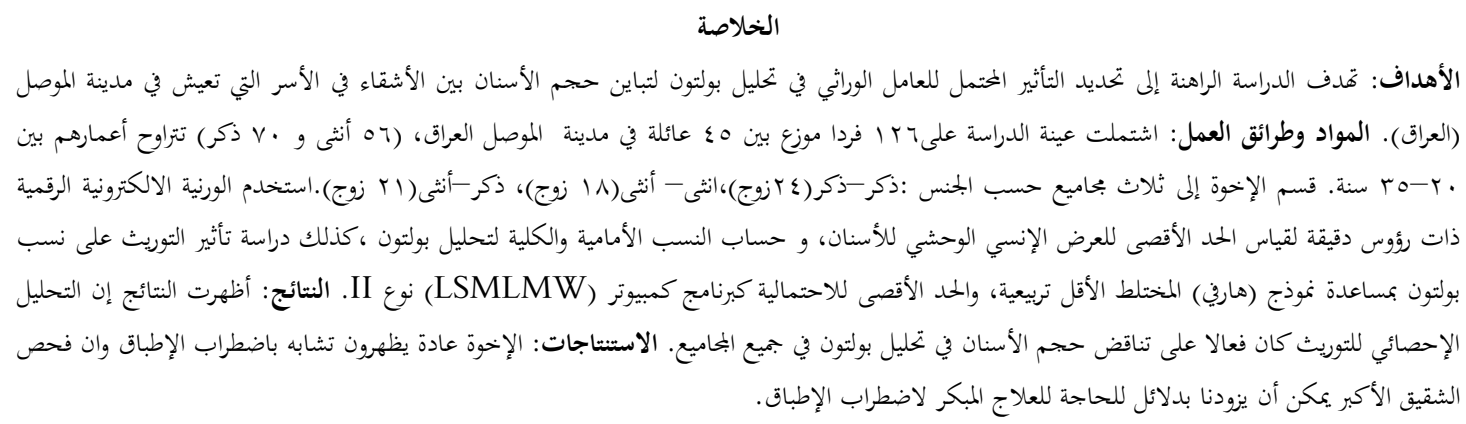

\begin{abstract}
Aims: To determine the possible effect of genetic factor on Bolton tooth size discrepancy between siblings in families living in Mosul City (Iraq). Material and methods: The study sample included 126 subjects distributed between 45 families in Mosul City (Iraq), (56 females and 70 males) whose ages ranged between (20-35) years. The sibling pairs were divided into three groups according to gender: male -male (24 pairs), female-female (18pairs), male-female (21 pairs). Electronic digital vernire with fine tips was used to measure the maximum mesio-distal widths of the teeth, and Bolton anterior and over all ratios was calculated. The effect of Heritability on Bolton ratios was studied by means of Harvey's mixed model least-squares and maximum likelihood computer program (LSMLMW) model type II. Results: Statistical analysis showed that Heritability was effective on Bolton tooth-size discrepancy in all groups, with the higher means for the anterior and over all ratios are for the male- male group. While the female-male group showed the lowest mean for the anterior ratio and the female -female group showed the lowest mean for the overall ratio. Conclusions: Siblings showed similar malocclusions, and examination of older sibling can provide clues to the need for interception and early treatment of malocclusion.
\end{abstract}

Key wards: Heritability, Genetics, Bolton analysis.

Al-Shahery W GH. Bolton Tooth Size Discrepancy among Mosul Families. Al-Rafidain Dent J. 2013; 13(1): 122-127.

Received: 19/9/2011 Sent to Referees: 22/9/2011 Accepted for Publication: 17/11/2011

\section{INTRODUCTION}

The main goal in comprehensive orthodontic treatment is to obtain optimal final occlusion, overbite and overjet. It has been found that tooth size discrepancies of the maxillary and mandibular arches is an important factor for achieving this goal. ${ }^{(1-}$

There are many factors that influence the variations in tooth size discrepancy, ${ }^{(4)}$ such as the type of gender: some authors found no significant differences either for Bolton anterior or over all ratios between females and males among different malocclusion groups, ${ }^{(2,3,5)}$ however, others found significant difference in tooth size discrepancy between sexes. ${ }^{(6-8)}$ It is sug- gested that tooth size discrepancy differs between various racial or ethnic groups, ${ }^{9-}$ ${ }^{11)}$ while Endo et al., ${ }^{(12)}$ stated that Bolton's values can be used with confidence for Japanese orthodontic population.

A strong influence of heredity on facial features is obvious, inherited characteristics, and comparing identical twins, fraternal twins can produce malocclusion, and ordinary siblings, an estimate of the heritability of any characteristic can be determined. ${ }^{(13)}$

Variation in tooth size is under a high degree of genetic control. There are difficulties in separating the various genetic and environmental factors. ${ }^{(14)}$ 
In clinical orthodontics, each malocclusion occupies its own distinctive slot in the genetic and environmental spectrum and, therefore, the diagnostic goal is to determine the relative contribution of genetics and the environment. The greater the genetic component, the worse the prognosis for a successful outcome might be by means of orthodontic intervention. ${ }^{(15,16)}$

The heritability assessments are undertaken according to narrow sense of heritability $\left(h^{2}\right)$, which is the proportions of trait's variation that, under ideal simplified conditions is attributed to genetic variation , this ratio of additive genetic to total (additive genetic plus environmental) variation does not take into account gene-togene interaction (dominance and epistasis) or gene-environment interaction. ${ }^{(17)}$

The purpose of this study is to evaluate the possible effects of genetic factor on the results of Bolton analysis.

\section{MATERIALS AND METHODS}

The sample of this study consisted of 126 subjects distributed between 45 families in Mosul City, Iraq, 56 females and 70 males whose ages ranged between 20-35 years were included in the study. The following selection criteria are used in selecting the sample:

1. Complete permanent dentition from right to left upper and lower first molars.

2. Class I molar relationship.

3. Absence of mesiodistal and occlusal abrasions or carries or Class II fillings.

4. Absence of dental prosthesis.

5. Absence of partially erupted teeth.

6. Absence of tooth anomalies in form, structure, and development.

Alginate impressions of the maxillary and mandibular dentitions were taken from each subject and stone casts were prepared. Impressions of the subjects with an orthodontic malocclusion are taken before their treatment.

Electronic digital verneir with fine tips (ISO-USA) is used to measure the maximum mesiodistal widths of the teeth, ${ }^{(18)}$ the accuracy of measurements was \pm 0.1 $\mathrm{mm}$.

The anterior and over all ratios are calculated according to Bolton ${ }^{(19)}$ with the fallowing formula: summandibular anterior 6 teeth sum maxillaryanterir 6 teeth

summanbibular 12 teeth

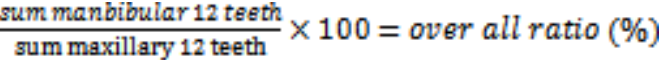

In order to eliminate any inaccuracy in the measurements performed, after 4 weeks remeasuring of 30 randomly selected casts to exclude intra-examiner bias and then submitting the data to student $\mathrm{t}-$ test. There are no statistically significant differences in the obtained results.

The sibling pairs are divided into three groups according to gender; male -male (24 pairs), female-female (18pairs), malefemale (21 pairs). Means, standard deviations (SD), ranges, and heritability values of Bolton anterior and over all ratios are computed for each group. The pooled group formed to compensate for the sex difference in tooth size after adding a correction factor, and by comparing the anterior and over all ratios of the male and female subjects and no statistical significant difference was found ( $p \geq 0.05$ and $p \geq 0.01$ ). Depending on these results, the sibling pairs in each group are pooled. ${ }^{(14,21)}$ For the pooled group, heritability estimate values $\left(h^{2}\right)$ are computed after the variation related to sex are eliminated although there is no gender difference.

The most simple heritability estimate value $\left(h^{2}\right)$ equation is:

$$
h^{2}=\frac{G}{G+E}
$$

Where $G$ is the variation of the trait's size among individuals because the individuals have different genotypes, and $\mathrm{E}$ is variation caused by the environment, and $\mathrm{G}+\mathrm{E}$ is the total phenotypic. $\frac{G}{G+E}$ is termed heritability in the narrow sense because it is the fraction of total variation due to the additive effects of genes. ${ }^{(20)}$

The heritability assessment of anterior and overall ratios is undertaken according to narrow sense of heritability $\left(h^{2}\right)$, which is computed according to Becker ${ }^{(2)}$ by the fallowing formula:

$$
h^{2}=\frac{\sigma_{g}^{\mathrm{z}}}{\sigma_{g}^{\mathrm{z}}+\sigma_{\mathrm{e}}^{\mathrm{z}}}
$$

When siblings of the same parents are used genetic variance is doubled and the formula is converted to:

$$
h^{2}=\frac{2 \sigma_{g}^{2}}{\sigma_{g}^{2}+\sigma_{\theta}^{2}}
$$

Where $\sigma_{\mathrm{e}}$ is the environmental vari- 
ance and $\sigma_{\mathrm{g}}$ is the genetic variance.

The data was analyzed using computer program Statistical analysis System SAS software (version 9.0, SAS Institute Inc., Cary ,NC. USA.2002) to perform descriptive analyzes and for the calculation of the genetic and environmental variances and to evaluate the heritability estimate values $\left(h^{2}\right)$, by Harvey's mixed model leastsquares and maximum likelihood computer program (LSMLMW) model type II was used. $^{(22)}$

\section{RESULTS}

The descriptive statistics that include
Mean, Standard Deviations, Minimum، Maximum values of Bolton anterior and over all ratios are listed in Table (1), and the results regarding the Heritability estimate coefficients $\left(h^{2}\right)$ values are shown in Table (2) and Figure (1).

The findings of the present study shows that the higher mean is for the anterior and over all ratios are for the malemale group. While the female-male group shows the lowest mean for the anterior ratio and the female - female group shows the lowest mean for the overall ratio.

Table (1): Descriptive statistics: Ranges, means, and standard deviations of Bolton's anterior and over all ratios.

\begin{tabular}{|c|c|c|c|c|c|c|}
\hline Group & No. & Variable & Mean & SD & Minimum & Maximum \\
\hline \multirow[b]{2}{*}{ Male- Male } & \multirow{2}{*}{24} & anterior ratio & 81.05 & 4.06 & 70.04 & 89.87 \\
\hline & & over all ratio & 92.99 & 2.03 & 88.47 & 96.81 \\
\hline \multirow{2}{*}{ Female- Female } & \multirow{2}{*}{18} & anterior ratio & 76.62 & 4.59 & 68.14 & 90.00 \\
\hline & & over all ratio & 91.92 & 2.90 & 85.88 & 99.55 \\
\hline \multirow{2}{*}{ Male-Female } & \multirow{2}{*}{21} & anterior ratio & 76.42 & 4.48 & 68.14 & 83.41 \\
\hline & & over all ratio & 91.93 & 3.06 & 85.88 & 97.27 \\
\hline \multirow{2}{*}{ Pooled group } & \multirow{2}{*}{44} & anterior ratio & 78.04 & 5.07 & 68.14 & 101.41 \\
\hline & & over all ratio & 92.14 & 3.16 & 82.19 & 97.17 \\
\hline
\end{tabular}

No: Number of pairs; SD: Standard deviation.

The results of Heritability estimate values $\left(h^{2}\right)$ shown in Table (2), are statistically significant for anterior ratios and significant for over all ratios in all groups. The Heritability coefficient $\left(h^{2}\right)$ of anterior ratios Figure (1) is higher in siblings of the same gender male- male group and fe- male - female group. Whereas in siblings of different gender group (male- female) it is the lowest .As for the Heritability coefficient $\left(h^{2}\right)$ of overall ratios Figure (1) the female-female group is the higher and the male-female group is the lowest.

Table (2): Heritability estimate coefficients $\left(h^{2}\right)$ values.

\begin{tabular}{|c|c|c|c|c|c|}
\hline Group & No. & Variable & $h^{2}$ & SE & p-value \\
\hline \multirow{2}{*}{ Male-Male } & \multirow{2}{*}{24} & Anterior ratio & 0.924 & 0.096 & $0.002 * *$ \\
\hline & & over all ratio & 0.738 & 0.090 & $0.012 *$ \\
\hline \multirow{2}{*}{$\begin{array}{c}\text { Female- } \\
\text { Female }\end{array}$} & \multirow{2}{*}{18} & Anterior ratio & 0.905 & 0.108 & $0.004 * *$ \\
\hline & & over all ratio & 0.780 & 0.103 & $0.011 *$ \\
\hline \multirow{2}{*}{ Male-Female } & \multirow{2}{*}{21} & Anterior ratio & 0.791 & 0.133 & $0.002 * *$ \\
\hline & & over all ratio & 0.575 & 0.114 & $0.015^{*}$ \\
\hline \multirow{2}{*}{ Pooled group } & \multirow{2}{*}{44} & Anterior ratio & 0.888 & 0.064 & $0.0001 * *$ \\
\hline & & over all ratio & 0.741 & 0.061 & $0.0001 * *$ \\
\hline
\end{tabular}

$h^{2}$ : Heritability estimate coefficient value; SE: Standard Error; No: number of pairs. ${ }^{*} p \leq 0.05$ : significant; ${ }^{* *} p \leq 0.01$ : highly significant. 


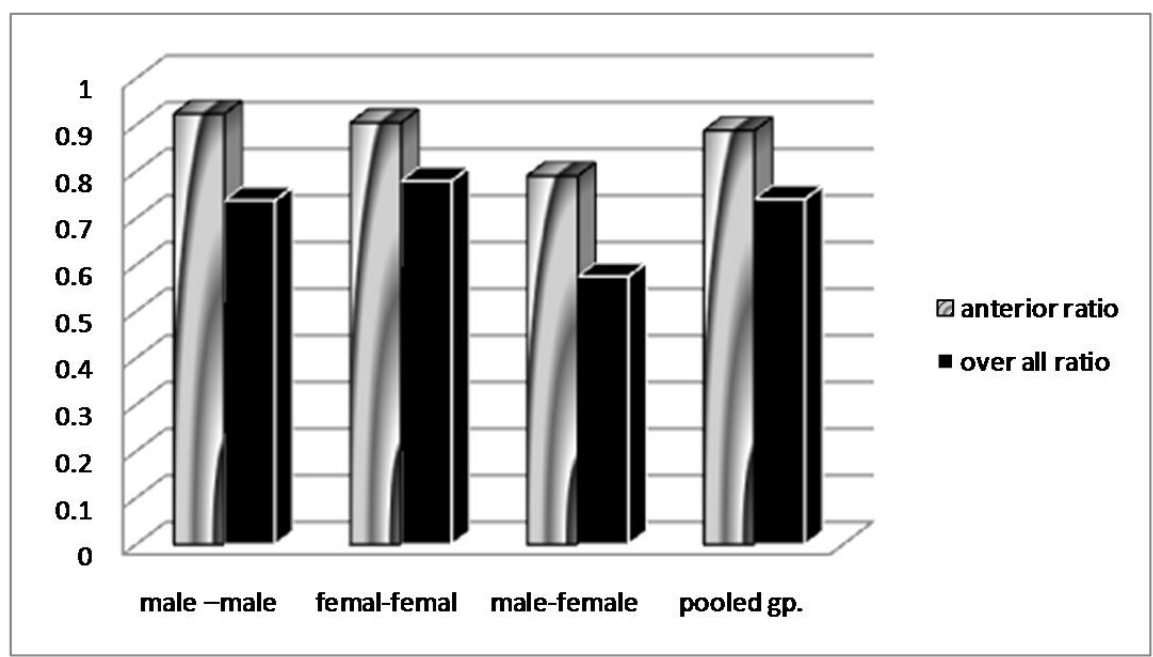

Figure (1): Heritability estimate coefficients $\left(h^{2}\right)$ values of Bolton's anterior and over all ratios.

\section{DISSCUSION}

In genetic studies, twines siblings, and parents and offspring are the most commonly used subjects. ${ }^{(23-25)}$ In this study, our reasons for choosing sibling pairs rather than twins are as follows: because the number of twins is small in a population and it is difficult to obtain enough pairs for a statistical study. In addition, twin pairs, especially monozygotic ones, give the same reply to similar environmental factors, and thus exaggerated $\left(h^{2}\right)$ values might be computed. ${ }^{(15,26)}$ In studies with parents and their offspring, tooth losses, restorative and orthodontic treatment of the parent generation makes pretreatment conditions difficult to estimate. ${ }^{(27-29)}$ Heritability can range from 0 (strict environmental determination) to 1.0 (strict genetic determination). ${ }^{(30)}$ In this study the Heritability estimate coefficient $\left(h^{2}\right)$ of the anterior and over all ratios were significant in all groups, which is explained by the fact that the siblings resemble each other not only because they share approximately half of their genes, but also because they experience similar pre, peri, and postnatal environment. ${ }^{(14)}$ In other words, two general factors could contribute to the familial resemblance: common genes and common environment, and the possibility of encountering a similar disorder in close relatives of patient with malocclu- sion is higher. ${ }^{(27-29,31)}$ The results of the present study does not agree completely with the results of Baydaş ${ }^{(14)}$ especially in the different gender group (male -female) for both the anterior and over all ratios, in Baydaş $^{(14)}$ study both ratios were not insignificant, while in this study, they are significant and this is explained by the fact that family members look alike not only because of genetics, but because of the shared environment they live in, influencing phenotypic similarities and enhancing phenotypic correlations. ${ }^{(31)}$ This point may be applicable to the closely related communities like in the sample of this study (Iraq: Mosul), which has closer family living relationship and style rather than what is seen in Western societies. ${ }^{(32)}$

In this study the anterior and over all ratios are significant in the different gender group, but it had lower Heritability coefficient values than the other groups and this can be explained that there is difference in the mesiodistal dimensions between the different genders. ${ }^{(6-8,33)}$

\section{CONCLUSIONS}

The siblings study method is effective for investigating genetically determined variables in orthodontic and other medical fields. In addition, siblings usually showed similar malocclusions, and examination of older sibling can provide clues to the need for interception and ear- 
ly treatment of malocclusion in younger siblings.

\section{REFERENCES}

1. Al-Khateeb SN, Alhaija ES. Tooth size discrepancies and arch parameters among different malocclusions in Jordanian sample. Angle Orthod. 2006; 76(3): 459-465.

2. Uysal T, Sari Z, Basciftci FA, Memili B. Intermaxillary tooth size discrepancy and malocclusion: Is there a relation? Angle Orthod. 2005; 75(2): 208-213.

3. Akyal S, Dogn S, Dinçer B, Erdinc A, ÖncagG.. Bolton tooth size discrepancies in skeletal Class I individuals presenting with different dental Angle classifications. Angle Orthod. 2005; 76(4): 637643.

4. Hong Q, Koirala R, Jun T , Li-na Y, Takagi S, Kawahara K, Kishimoto E, Shimizu T, Takamata T , K Nakano K, Okafuji O. A study about tooth size and arch width measurement. J Hard Tissue Biology. 2008; 17(3): 91-98.

5. Abduhl WN, Christian HS, Christian S, Mohammad K. Standardizing Interarch tooth- size harmony in Syrian population . Angle Orthod. 2005; 75(6): 996-999.

6. Santoro M, Ayoub ME, Pardi VA, Cangialosi TJ. Mesiodistal crown dimensions and tooth size discrepancy of the permanent dentition of Dominican. Angle Orthod. 2000; 70(4): 303-307.

7. Smith SS, Buschang PH, Watanabe E. Interarch tooth size relationships of 3 populations.' Does Bolton's analysis apply?' Am J Orthod Dentofacial Orthop. 2000; 117(2): 169- 174.

8. Uysal T, Sari Z. Intermaxillary tooth size discrepancy and mesiodistal crown dimensions for a Turkish population. Am $J$ Orthod Dentofacial Orthop. 2005; 128(2): 226-230.

9. Johe R S, Steinhart T, Sado N, Greenberg B, Jing S. Intermaxillary tooth- size discrepancies in different sexes, malocclusion groups, and ethnicities. Am J Orthod Dentofacial Orthop. 2010; 138 (5): 599607.

10.Jaiswal AK, Paudel KR. Applicability of Bolton's tooth size ratio for Nepalese population. J Nepal Dent Assoc. 2009; 10(2): 84-87.

11.O' Mahony G, Millett DT, Barry MK, Mcintyre GT, Cronin M S. Tooth size discrepancies in Irish orthodontic patients among different malocclusion groups. Angle Orthod 2011; 81(1): 132-135.

12.Endo T, Abe R, Kuroki H, Oka K, Shimooka S. Tooth size discrepancies among different malocclusion in a Japanese Orthodontic population. Angle Orthod. 2008; 78(6): 994-999.

13. Proffit WR. Contemporary Orthodontics $4^{\text {th }}$ ed. Mosby. St Louis. 2007; P: 199.

14.Baydaş B, Oktay H, Dağsuyu IM. The effect of heritability on Bolton tooth size discrepancy. Eur J Orthod. 2005; 27(1): 98-102.

15. Mossey PA. The Heritability of malocclusion :Part 2. The influence of genetics in malocclusion. British $J$ of Orthod. 1999; 26(3): 195-203.

16. Iwasaki L R, Crouch LD, Nickel JC. Genetic factors and tooth movement. Seminars Orthod. 2008; 14(2): 135-145.

17.Sprowls MW, Ward RE, Jamison PL , Hartsfield JK. Dental arch asymmetry, fluctuating dental asymmetry, and dental crowding: A comparison of tooth position and tooth size between antimeres. Seminars Orthod. 2008; 14(2): 157-165.

18. Moorrees CF,Thomsen SO, Jensen E, Yen PK. Mesiodistal crown diameters of deciduous and permanent teeth in individuals. J Dent Res.1957; 36(1): 39-47.

19.Bolton WA. Disharmony in tooth size and its relation to the analysis and treatment of malocclusion. Angle Orthod. 1958; 28(3): 113-130.

20.Bolton WA. The clinical application of a tooth-size analysis. Am J Orthod. 1962; 48(7): 504-529.

21.Harris EF. Interpreting heritability estimates in orthodontic literature. Seminars in Orthod. 2008; 14(2): 125-134.

22.Becker WA. Manual of Quantative Genetics. $3^{\text {rd }}$ Ed. Washington State University. Pullman, Washington. 1975; Pp: 99-163.

23.Harris JE, Kowalski CJ, Walker SJ. Interfamilial dentofacial associations for Class II, Division 1 probands. Am J Orthod. 1975; 67(5): 563-570.

24.Johannsdottir B, Thorarinsson F, Thordarson A, Magnusson TE. Heritability of craniofacial characteristics between parents and offspring estimated from lateral cephalograms. Am J Orthod Dentofacial Orthop. 2005; 127(2): 200-207. 
25.Corruccini RS, Potter RH. Genetic analysis of occlusal variation in twins. Am J Orthod. 1980; 78(2): 140-54.

26.127Lundström A. Nature versus nurture in dento-facial variation. Eur J Orthod. 1984; 6(2): 77-91.

27.Harris EF, Smith RJ. A study of occlusion and arch widths in families. Am J Orthod. 1980; 78(2): 155-163.

28.Harris EF, Johnson MG. Heritability of craniometric and occlusal variables. A longitudinal siblings analysis. Am J Orthod Dentofacial Orthop.1991; 99(3): 258-268.

29.Harris EF, Smith RJ. Occlusion and arch size in families. A principal components analysis. Angle Orthod. 1982; 52(2): 135143.

30.Michalowicz BS, Aepplp DP, Kuba RK,
Bereuter JE, Conry JP, Segal NL, Bouchard TJ, Pihlstrom Jr, Pihlstrom BL. A twin study of genetic variation in proportional radiographic alveolar bone height. $J$ Dent Res.1991; 70(11): 1431-1435.

31.Baydaş B, Erdem A, Yavuz I, Ceylan I. Heritability of facial proportions and softtissue profile characteristics in Turkish Anatolian siblings. Am J Orthod Dentofacial Orthop. 2007; 131(4): 504-509.

32.Alkudhairi TD, Alkofide EA. Cephalometric craniofacial features in Saudi parents and their offspring. Angle Orthod. 2010; 80(6): 1010-1017.

33. Strujić M, Milošević SA, Meštrović S, Šalj M . Tooth size discrepancy in orthodontic patients among different malocclusion groups. Eurp J Orthod. 2009; 31(6): 584-589. 